\title{
Ciência e política pública na perspectiva dos gestores: clivagens e confluências
}

\section{Maria José Teixeira Carneiro \& Laila Thomaz Sandroni*}

Resumo: O presente artigo apresenta uma reflexão sobre a articulação ciência e políticas públicas a partir de entrevistas com gestores de dois ministérios. A questão orientadora da pesquisa foi identificar o lugar atribuído ao conhecimento científico no processo de formulação de políticas e normas técnicas. Para tal foi necessário esclarecer as percepções de ciência que informam as práticas dos gestores. Como base teórica, partimos de uma crítica à noção de evidence-based policy, que propõe a instrumentalização do conhecimento científico pela política, para chegarmos à noção de "coprodução" proposta por Jasanoff. Essa autora sustenta que ciência, política e cultura são coproduzidas, sendo impossível estabelecer fronteiras nítidas entre elas. Concluímos que prevalece, no universo pesquisado, a valoração da objetividade da ciência como fundamental para a legitimação das decisões no campo da política (policy). Mas, ao mesmo tempo, demanda-se maior envolvimento da ciência com assuntos de interesse governamental. Observou-se também que apesar das dificuldades apontadas nessa relação, os discursos e as práticas dos gestores estão permeados de referências ao conhecimento científico.

Palavras-chave: política baseada em evidências, coprodução, gestores públicos, política pública, ciência e sociedade.

\section{Introdução}

M uito se tem debatido e publicado a respeito da contribuição do conhecimento científico para as políticas públicas na Europa e nos Estados Unidos, a partir de uma sucessão variada de perspectivas teóricas. No Brasil em particular, o debate teve como foco as relações entre conhecimento e poder no âmbito estatal, a partir da análise do funcionamento da tecnoburocracia e dos procedimentos de tomada de decisão, mas não especificamente da utilização do conhecimento científico na elaboração e implementação de políticas públicas, como propomos neste artigo. Esse campo de conhecimento, de difusão crescente nas últimas duas décadas, aparece com força no âmbito dos estudos sociais da ciência e tecnologia na Europa e nos Estados Unidos, constituindo fértil campo de discussão, ainda pouco explorado, no âmbito do qual este trabalho pretende situar-se. Nossa abordagem está inserida no amplo debate sobre os usos sociais da ciência, observando, especificamente, o caso de sua contribuição na formulação de políticas e medidas públicas.

\footnotetext{
* Maria José Teixeira Carneiro é antropóloga, professora titular da Universidade Federal Rural do Rio de Janeiro, Seropédica (RJ), Brasil, Programa de Pós-Graduação de Ciências Sociais em Desenvolvimento, Agricultura e Sociedade, bolsista do CNPq, coordenadora do Grupo de Pesquisa Ciência, Natureza, Informação e Saberes (Cinais). $<$ mjtcarneiro@gmail. com>.

Laila Thomaz Sandron é socióloga, mestre e doutoranda do Programa de Pós-Graduação de Ciências Sociais em Desenvolvimento, Agricultura e Sociedade na Universidade Federal Rural do Rio de Janeiro, Seropédica (RJ), Brasil, integrante do Grupo de Pesquisa Ciência, Natureza, Informações e Saberes (Cinais). $<$ lailasandroni@ hotmail.com>
} 
1. Esta questão foi desenvolvida em Carneiro \& Palm (2017).

2. Estamos empregando o termo "política", neste artigo, em dois sentidos: como campo social com organicidade própria onde se manifestam relações de poder e lógicas específicas de interação entre os atores sociais (no sentido de politics), próximo da noção de campo em Bourdieu; e no sentido das ações governamentais na forma de normas, regras e princípios, ou seja, "políticas públicas", o que aproxima esse termo ao equivalente em inglês policy. Para um desenvolvimento dessa distinção, ver Frey (2000).
O presente artigo apresenta uma reflexão, a partir dos dados gerados por pesquisa junto a gestores públicos, sobre a articulação entre ciência e políticas públicas que versem especificamente sobre temas de interface entre agricultura familiar e conservação da biodiversidade. Ao todo, a pesquisa envolveu 35 gestores de dois ministérios, sendo 16 do Ministério do Desenvolvimento Agrário (MDA) e 19 do Ministério do Meio Ambiente (MMA). Foram realizadas 21 entrevistas individuais e dois grupos focais, um no MMA, com oito participantes e o segundo no MDA com cinco participantes, durante o ano de 2013. As perguntas semidiretivas realizadas tinham como objetivo questionar os gestores sobre o lugar que atribuíam ao conhecimento científico em suas atividades, principalmente no processo de formulação de políticas públicas. Além disso, a pesquisa visava identificar a existência de alguma lacuna de conhecimento que pudesse ser traduzida em uma questão passível de ser respondida a partir do conhecimento científico disponível ${ }^{1}$.

O artigo é dividido em duas sessões, além desta introdução e das considerações finais. Iniciamos com a apresentação da abordagem conhecida como evidence-based policy (política baseada em evidências) sobre a qual desenvolvemos uma crítica à luz da perspectiva da coprodução entre ciência, política e sociedade ou, nos termos da Jasanoff (2004), entre ciência, Estado e cultura. Em seguida, apresentamos os resultados da pesquisa junto aos gestores sobre suas percepções de ciência que informam suas ações e visões críticas sobre os usos do conhecimento científico no âmbito do Estado, para, então, aprofundar a compreensão sobre o papel atribuído ao conhecimento científico na elaboração de políticas e notas técnicas. Finalmente, nas considerações finais, sustentamos que predomina entre os gestores uma visão ambígua da ciência, que ora aparece como narrativa profundamente apartada da política ${ }^{2}$, ora como campo legitimado de geração de dados e de tecnologias concebidos como instrumentos importantes na fundamentação e justificação das disputas internas e externas à prática governamental. Em seguida, apresentamos algumas reflexões sobre os limites e as possibilidades da contribuição do conhecimento científico às políticas públicas em um Estado democrático de direito com características como as do Brasil. Pretendemos, assim, contribuir para o debate, cientes dos limites que um estudo de caso impõe. O fato de não termos encontrado na bibliografia disponível nos periódicos brasileiros de ciências sociais, até esse momento, nenhum estudo semelhante a este, aumenta nossa responsabilidade e os riscos de erros. Contudo, assumindo-os, colocamos em debate nossa reflexão e análise na expectativa de provocar novos estudos e aprofundar o conhecimento sobre o tema. 


\section{Da evidence-based policy à coprodução}

Antes de apresentarmos os resultados da pesquisa, importa apresentar uma breve explanação do caminho percorrido na construção da perspectiva teórica que será acionada. As questões aqui levantadas fazem parte de uma pesquisa em contínuo desenvolvimento desde $2007^{3}$. Naquele momento, estávamos procurando aplicar, no Brasil, a metodologia da evidence-based policy (política baseada em evidências - PBE), ainda pouco conhecida no país, que visa estreitar os canais de comunicação entre ciência e política. Essa política parte do pressuposto de que seria imperativo estimular a aproximação entre ciência e política, no intuito de suprimir ou diminuir a lacuna que vigora na relação entre cientistas e gestores. Nessa direção, defende que o amplo acesso ao maior número de evidências científicas sobre uma determinada questão ampliaria o leque de opções dos gestores, contribuindo assim para a formulação de políticas mais eficazes. Iniciada na área da saúde, essa metodologia avançou em vários campos, mas, sobretudo, no que diz respeito às políticas voltadas para a conservação da biodiversidade (Sutherland et alii, 2004). Para essa aproximação, a PBE apresenta uma serie de instrumentos com o objetivo de orientar e tornar mais eficiente essa relação ${ }^{4}$.

Com o desenvolvimento da pesquisa e uma maior familiaridade com a bibliografia sobre a PBE, passamos a compreender que os instrumentos propostos e os objetivos vinculados estão imbricados a uma determinada concepção de ciência alinhada à ideia de objetividade. Nesses termos, não reconhece outras formas de conhecimento e procedimentos (como o conhecimento tácito dos gestores, os saberes locais etc.) que permeiam essa intermediação, e isso por considerá-los valorativos ou opinativos. Percebemos, então, as implicações dessa abordagem que, partindo da valorização do conhecimento científico como isento de valor, imparcial e sustentado por conhecimentos validados empiricamente (as evidências), pressupõe uma submissão da política à racionalidade instrumental da ciência. Em decorrência da própria dinâmica da pesquisa, que revelou uma realidade bastante distante da descrita na literatura sobre a PBE, e refletindo a partir de novas leituras, chegou-se a uma visão crítica desta abordagem; percebeu-se que ela se limitava a buscar mecanismos mais eficazes na instrumentalização do conhecimento científico por parte dos gestores, atribuindo a esses a responsabilidade por aprimorar o uso do conhecimento na formulação de políticas públicas.

Para além das discussões dentro do contexto específico da metodologia da PBE, autores do campo mais amplo de análise de políticas públicas têm destacado a importância dos valores e de outras formas de conhecimento, não necessariamente "ob-
3. Projetos

relacionados:

"Agriculture et

développement durable dans les problématiques d'evidencebased policy", coordenado por Catherine Laurent (Institut National de la Recherche Agronomique

- Inra, França 2007-2010); “A comunicação entre ciência e políticas públicas: o uso da metodologia baseada em evidências na interface biodiversidadeagricultura familiar", coordenado por M. J. Carneiro (20122016); "Aproximando ciência e políticas públicas no campo da agricultura familiar e biodiversidade", coordenado por M. J. Carneiro (20142016).

4. Para um análise mais aprofundada dessa abordagem, ver Catherine Laurent et alii (2009); Andrew Pullin, Teri Knight \& Andrew Watkinson (2009). 
jetivos", na formulação de políticas públicas. Em uma crítica ao positivismo expresso em análises do tipo da PBE, autores que se filiam a um movimento teórico que ficou conhecido como argumentative turn consideram que o planejamento estatal e o planejamento das políticas públicas estão necessariamente atrelados a um processo de disputas discursivas, permeado pela construção de verdades e por modos de representação que, ao mesmo tempo, permitem e restringem as possibilidades de atuação dos gestores (Fischer \& Forester, 1993; 2002). Portanto, uma perspectiva que leve em conta a importância da argumentação, da construção de categorias, dos conceitos e enquadramentos embutidos na elaboração e implementação de políticas públicas levaria a uma análise crítica da produção dos gestores, questionando a objetividade destes processos e ainda os papéis da ciência neste contexto. Outra vertente das análises de políticas públicas é a chamada "abordagem cognitiva": essa enfatiza o papel das crenças, ideias e representações elaboradas pelos atores em sua relação com o mundo como fundamentais para a compreensão das políticas públicas (Muller, 2008 apud Grisa, 2012). Como bem sintetizou Cátia Grisa,

esta corrente [análise cognitiva] compreende as políticas públicas como o resultado de interações sociais que dão lugar à produção de ideias, representações e valores comuns. Como afirma Surel (2000), as políticas públicas são construídas pelas crenças comuns de um conjunto de atores (públicos e privados), as quais definem a maneira como esses atores percebem e interpretam os problemas públicos e concebem respostas aos mesmos (Grisa,2012: 32).

Outros autores, como Isaac Nevo e Vered Slonim-Nevo (2011), incorporaram à PBE visões menos impositivas, mais próximas à perspectiva da virada argumentativa. Conjecturam na direção de uma flexibilização do método baseado em evidências propondo que as práticas políticas fossem "informadas", ao invés de "baseadas" em evidências. Distinguem assim, a EBP da evidence informed pratice (EIP), reconhecendo o conhecimento científico como um dos campos, dentre outros, a serem acessados durante a formulação de políticas, incluindo nesse processo a prática dos gestores e os valores dos beneficiários (clients). Nesta visão, a ciência não estaria acima de outras formas de conhecimento capazes de contribuir para a construção de políticas mais eficazes, seria apenas mais uma no rol de conhecimentos passíveis de serem acessados para informar a prática dos gestores.

Entretanto, mesmo nessa vertente menos tecnocrata predomina uma visão baseada na instrumentalização direta da ciência (tida como expressão dos "fatos" e isenta de valores) no processo de decisão política. Além disso, subjaz uma percepção de política e de ciência como campos absolutamente separados (purificados) e fechados em torno de si mesmos, o que justificaria a busca de instrumentos para a cons- 
trução de uma passarela capaz de superar o abismo que os separa. A partir dessas reflexões críticas, perguntamos: como esse abismo é construído? O que subjaz à ideia de que uma maior aproximação entre ciência e política seja desejável? Chegamos, então, à necessidade de identificar as representações de ciência que embasam essa visão dicotômica, isso porque acreditamos que desenvolver uma pesquisa sobre essa relação exige esclarecer as percepções dos atores sobre ciência a orientarem essa articulação.

Pouco a pouco, conforme a pesquisa foi avançando, nos distanciamos mais e mais da abordagem original (sustentada na PBE), o que exigiu recorrer a outro quadro teórico que nos permitisse identificar, a partir de outra perspectiva, as relações entre ciência e política pública. Procuramos nos afastar de uma concepção sustentada na separação entre os dois campos, segundo a qual a ciência seria o campo do conhecimento objetivo empiricamente validado, enquanto a política o espaço dos valores e da ideologia. Foi, então, que nos aproximamos do diálogo com o "idioma da coprodução" (Jasanoff, 2004). Apesar de bastante explorado na Europa, nos Estados Unidos e na África, este fecundo horizonte teórico foi pouco trabalhado no Brasil e na América Latina, constituindo um campo aberto para experimentações. O referido idioma sugere que as formas de elaborar políticas, em um determinado contexto sócio-histórico, estão intimamente relacionadas às formas de ordenamento preponderantemente legítimas naquele momento, legitimidade esta que se enraíza no ambiente cultural deste mesmo contexto. Neste sentido, cultura, política e ciência só podem se produzir conjuntamente (Jasanoff, 2004).

É bom acionar aqui Yaron Ezhari (2004) que, na esteira deste mesmo pensamento, argumenta que a formação e consolidação das democracias modernas e do discurso científico ocorreram simultaneamente, em correlação. A reorganização das maneiras de se elaborar políticas fundamentadas no discurso científico criou algumas das características centrais das democracias contemporâneas que podem ser percebidas, por exemplo, através do crescente emprego de um vocabulário técnico instrumental no campo do discurso político, do uso da metáfora da máquina para falar sobre as formas de ação do Estado, da incorporação das ideias de confiança e transparência das políticas de Estado, da fé na possibilidade de discussão racional dos pontos de discordância visando à geração de consensos entre os cidadãos. Ezhari (2004) entende que foi na relação com o racionalismo científico que se constituiu a ideia de democracia com base no "consenso" e a formação dos Estados democráticos de direito como os conhecemos hoje. É claro que essas atribuições do Estado não revestem a mesma força nos países centrais e nas chamadas "sociedades periféricas". Isto não quer dizer que nos países centrais esta racionalidade se implemente por completo; como nos aponta Bruno Latour (1994), as sociedades 
5. A título de ilustração, cabe mencionar, na Inglaterra, o Department for Environment, Food and Rural Affairs (Defra) - informação disponivel em: $<$ http://www.defra. gov.uk/evidence /index>-e os diversos Centre for Evidence em áreas da saúde, da educação, da segurança, do meio ambiente etc., com o objetivo de prover sínteses do conhecimento acadêmico atualizado sobre questões propostas pelo governo. Ver, por exemplo, o Centre for Evidence-based Conservation, sediado na Universidade de Bangor <http:// www.cebc.bangor. ac.uk>. Experiências semelhantes estão presentes em outros países como o Canadá, a Austrália e países africanos de colonização inglesa. ocidentais e os Estados que as embasam jamais foram modernos. Como aponta Fischer, o debate democrático e as decisões no campo da política (politcs) não obedecem a racionalidades de base científica nem se sustentam na busca de uma única solução - a mais eficiente - como parecem pressupor certos defensores da EBP. Entretanto, reconhecemos que a força de atuação, até mesmo performática, do Estado calcado numa racionalidade científica esteve mais profundamente instalada em determinadas regiões geopolíticas do mundo ocidental que em outras. No caso do Brasil, por exemplo, acreditamos ser necessário levar em conta que setores do Estado, apesar de reconhecerem a legitimidade deste modelo de democracia alinhado à racionalidade científica, recorrem também a práticas marcadas pela pessoalidade até mesmo para demandar consultas ou assessoramentos de especialistas, como observamos na presente pesquisa. Por outro lado, caberia perguntar até que ponto essas relações pessoais também estariam presentes nos países centrais, mas simplesmente se tornam invisíveis ou não identificadas porque são desdenhadas, o que parece ser o caso dos países que institucionalizam a prática PBE em suas instâncias governamentais, como a Inglaterra ${ }^{5}$. Caberia indagar também sobre as reais diferenças entre o contexto patrimonialista brasileiro e aquele dos países centrais, dada a compreensão de que a tecnocracia se coloca enfaticamente como elemento importante nas relações de poder, e não necessariamente traduz uma "maior racionalidade" do Estado. Mas isso é assunto para outra pesquisa.

Essas considerações nos fazem crer que o papel da ciência na política - e, especificamente, na formulação de políticas públicas - está não penas no acesso a informações científicas ou na opinião de especialistas externos à máquina estatal, mas também na própria maneira de pensar as políticas e o modelo burocrático de atuação do Estado. Como nos lembra Jasanoff (2004), a democracia moderna está baseada (dependendo do país, em maior ou menor grau) em uma cultura de valorização da racionalidade científica e do pensamento objetivamente produzido. Assim, entendemos que, para além das "tentativas de supressão das lacunas entre ciência e política”, preconizada pela PBE, há política na ciência e há conhecimento científico na política, na medida em que ambas estão ancoradas em uma mesma cultura - "moderna ocidental" - que possui a objetividade científica como valor, sendo a metodologia PBE uma das manifestações desta cultura.

A título de ilustração, lembramos que a cultura de valorização do conhecimento científico materializa-se, por exemplo, na exigência de formação técnico-científica (chegando ao nível de pós-graduação) para a ocupação de cargos de gestão governamental ou na capacitação por meio de cursos oferecidos aos gestores dentro do próprio contexto estatal, o que demonstra a dificuldade de se estabelecer a separação entre academia e gestão pública nos dias de hoje. A familiaridade com o 
universo acadêmico e os procedimentos científicos entre os gestores públicos pôde ser percebida de diversas maneiras: pela familiaridade com sites de busca; pela interação entre gestores, principalmente os dos mais altos escalões, com intelectuais, professores universitários e pesquisadores que ocupam funções de assessores; pela ampla utilização de termos técnico-científicos para explicar suas funções e formas de atuação. Assim, observamos que é impossível estabelecer uma distinção precisa entre o conhecimento elaborado intramuros da academia e o conhecimento ou a informação técnica elaborado ou adquirido para fins operacionais segundo os interesses da política pública, como nos sugere a resposta de uma gestora do MDA a uma de nossas questões:

P: Mas, qual é a principal dificuldade de acessar o conhecimento científico, não só o das universidades em si?

R: Eu não sei se eu sei responder quanto a estas dificuldades não, esta vida é tão corrida... Eu não sei se estou usando a informação científica ou quando estou usando o conhecimento empírico que a gente adquiriu ao longo da vida.

Observações como essa permitiram perceber o grau de inadequação de nossa abordagem inicial baseada ainda nos princípios e pressupostos da PBE. O recurso ao conhecimento científico no cotidiano dos gestores não era de exigência institucional, do mesmo modo, os gestores não percebiam uma objetivação do conhecimento científico em suas práticas. Percebemos também que este era um assunto sobre o qual os gestores não tinham um discurso pronto, como é de praxe nos temas mais próximos às suas funções. Assim, suas respostas aos nossos questionamentos eram permeadas por uma ambiguidade no que se refere à utilização do conhecimento científico e à importância deste em suas ações cotidianas na administração pública. Apesar de observamos que a ciência estava, de algum modo, presente na prática e nos discursos dos gestores, não havia a demanda pela facilitação do "acesso sistemático" ao "conhecimento disponível", tal qual sugere a PBE. Com surpresa verificamos que os ministérios não oferecem acesso ao portal de periódicos da Coordenação de Aperfeiçoamento de Pessoal de Nível Superior (Capes) aos seus técnicos como também são raros aqueles que conhecem ou recorrem à base Scientific Electronic Library Online (SCIELO) para se municiarem de informações para a sua prática profissional. Essas observações empíricas nos indicam que nesse pequeno universo, a relação entre o conhecimento técnico-científico e a prática da formulação de políticas públicas se manifesta mais nos termos de uma coprodução, no sentido de uma interferência mútua e subjetiva, e não como resultado da busca por uma solução obtida a partir de textos acadêmicos, como pretendem algumas práticas institucionalizadas em alguns países, sobretudo os de cultura anglo-saxã. 
Entretanto, essa imbricação que expressa - a nosso ver - uma dinâmica mais próxima à de "coprodução" entre saberes técnico-científicos, interesse político e sociedade, não implica a negação das diferenças entre ciência e política, seja nos termos das representações, seja nos termos dos modos de ordenamento (Law, 1994). Se ciência e política estão intrinsecamente relacionadas na sociedade e na cultura ocidental - como sugere Jasanoff -, também não é correto dizer que são a mesma coisa. Segundo John Law (1994), os modos de ordenamento são as variadas formas segundo as quais compreendemos e explicamos a realidade social na qual vivemos. O autor propõe uma sociologia dos verbos que remeta à condição processual e de constante transformação de todas as maneiras de organização social. Compreende, portanto, que não há apenas uma ordem social a ser revelada, mas processos plurais e incompletos de modos de ordenamento social. Na medida em que são incompletos e dinâmicos, esses ordenamentos podem se cruzar e se retroalimentar, como ocorre no campo que ora estamos analisando. Law aponta ainda que, apesar de imbricados, os ordenamentos operam esforços de purificação, ou seja, constituem sua legitimidade ao se diferenciar perante outras formas de compreensão do mundo. O caso em estudo ilustra um modo como esse "esforço" de marcar diferenças e estabelecer fronteiras se expressa num universo delimitado. Os atores sociais envolvidos, apesar de estarem implicados em ambos os campos, operacionalizam processos de diferenciação que reiteram fronteiras e os posiciona em um dos lados. Percebe-se, articulando os dois tipos de discursos, que esse processo é uma via de mão dupla onde cada um dos lados atua no sentido de marcar as fronteiras e diferenças reforçando, assim, uma legitimação do modo de ordenamento a que estão referidos. Gestores (ou "técnicos") e cientistas (ou "especialistas") expressam esse movimento de aproximação e distanciamento ao reforçarem, em seus discursos, a "autonomia" e a autoridade epistemológica perante o "outro".

Embora se reconheça a presença da ciência na atuação cotidiana, bem como em sua formação, gestores se contrapõem às formas de pensar e atuar dos cientistas. Aqui, as distinções entre ciência e política, no âmbito mais amplo, se expressam no modo como elas são passíveis de serem ordenadas, relacionadas e sintetizadas pelos gestores. Neste sentido, não cabe refletir somente sobre uma melhoria nos "canais de comunicação" entre a produção acadêmica e a formulação de políticas públicas, facilitando o acesso dos gestores ao conhecimento produzido sobre determinados assuntos, como prescreve a PBE, mas de compreender como se dá a imbricação dessas duas formas de ordenamento do mundo e os usos sociais que delas é feito. Como lembra Jasanof (2004) a respeito do idioma da coprodução, é na própria relação de alteridade que a diferença entre os campos distintos é produzida, distanciando práticas e formas de compreensão do mundo. Acreditamos que os discursos dos gestores, aqui analisados, como os dos cientistas, analisados em outra ocasião 
(Delatin, Carneiro \& Sandroni, 2015), expressam os limites e as possibilidades, as clivagens e as confluências.

É partindo deste jogo entre coprodução e construção ativa das diferenças entre os modos de ordenamento que procuraremos analisar as percepções sobre ciência no discurso dos gestores. O intuito, aqui, ao identificá-las, é verificar como se manifestam nessa rede que interliga, confunde e, ao mesmo tempo, diferencia conhecimento científico e políticas públicas.

\section{Percepções de ciência}

Nesta seção, buscamos correlacionar as diferentes formas de compreender a ciência presentes nos discursos dos gestores entrevistados, com as visões acerca da utilidade deste tipo de conhecimento na formulação de políticas públicas. Partimos da compreensão de que identificar as diferentes percepções sobre ciência que atravessam as diversas falas dos gestores pode oferecer algumas pistas para o reconhecimento do ambiente cultural no qual elas se enraízam e dos processos através dos quais ciência e política se entrelaçam e se separam simultaneamente.

O primeiro ponto de especial interesse para a presente pesquisa é que nenhum entrevistado, independentemente da posição ocupada na organização hierárquica dos ministérios, negou que o conhecimento científico tivesse importância como subsídio para a tomada de decisões sobre as políticas públicas ${ }^{6}$. Porém, é importante considerar a possível indução dessas respostas, primeiro devido à formulação da questão que, partindo dos princípios da PBE colocava essa relação como um pressuposto; segundo, em decorrência do fato de a entrevista ser realizada por pesquisadoras acadêmicas, o que pode ter constrangido os gestores a responderem positivamente. De qualquer forma, sobressai o fato de que dos 37 entrevistados todos tenham respondido afirmativamente, sem hesitar, à questão:

Segundo a sua experiência, o senhor acha que o conhecimento científico e os resultados de pesquisas acadêmicas contribuem na formulação de políticas ou na tomada de decisão sobre elas?

As respostas podem ter sido motivadas pela experiência pessoal do gestor, habituado à relação com pesquisadores ou acadêmicos, seja na própria relação de trabalho, seja nos espaços acadêmicos (muitos deles com passagem por cursos de pós-graduação). Mas pode também apontar para uma cultura de valorização do conhecimento científico como constituinte do Estado democrático de direito, conforme já nos referimos anteriormente. Contudo entendemos que essa "valorização" deve ser 
considerada dentro de um contexto - a sociedade democrática moderna - em que o conhecimento científico é reconhecido como critério de verdade, de neutralidade e de confiabilidade, em uma palavra, como critério de legitimidade de forte valor no campo das disputas sobre decisões em políticas públicas. Desse modo, podem existir "bons" e "maus" cientistas, mas o lugar da ciência como produtora de verdades não é colocado em xeque. Reconhecem-se dificuldades "práticas" nessa colaboração, mas estas são vistas, de modo geral, como passíveis de superação, em maior ou menor grau.

Os problemas identificados pelos gestores têm menos a ver com a forma de construção da ciência e da política e mais com as dificuldades na construção da passarela para superar o suposto abismo existente entre elas. Mas, prepondera uma percepção de que a ciência, como produtora da "verdade" - de um conhecimento "objetivo" - está mais próxima da realidade do que outras formas de produção do saber. Assim, ela é incumbida - ou deveria ser - de oferecer respostas às questões da sociedade e da política em particular, mesmo que haja dificuldades nessa interlocução. Ao mesmo tempo, reconhecem que, devido à distância que predomina entre os campos da política pública e da academia, a experiência pessoal e o conhecimento que dela resulta constituem as bases mais fundamentais das formulações de políticas. Apesar de o conhecimento científico ser valorizado, as descrições acerca dos processos de formulação das políticas revelaram um papel pouco expressivo da ciência, seja a que é produzida nos centros de pesquisa, seja a que se encontra disponível nas bases de dados. Confirma-se, assim, o que já havia sido observado em pesquisa anterior: o recurso à ciência pelos gestores públicos ocorre, normalmente, de forma casuística, sem obedecer a uma sistemática que coloque à disposição do gestor o conjunto de conhecimento disponível sobre uma determinada questão, de modo a ampliar o leque de opções para a tomada de decisão, como sustenta a PBE (Carneiro, Leite \& Bruni, 2009).

A cultura de valorização da ciência se manifesta, portanto - de maneira específica no caso estudado -, acionando mais a legitimidade social do conhecimento científico do que a sistematização da grande miríade de conhecimento produzido sobre um determinado tema. Agir "cientificamente", ou possuir um título acadêmico, é a maneira como se resolve, no universo pesquisado, a necessidade de legitimação científica para determinadas decisões. De qualquer maneira, ingênuo supor uma relação linear entre ciência e política, na qual a fundamentação científica determinaria a formulação de políticas mais adequadas ou mais eficientes, corroborando uma visão positivista de ciência que, como dissemos anteriormente, se apoia numa hierarquização dos conhecimentos a partir da crença na neutralidade e racionalidade científicas, com a qual certamente não concordamos. Nossa crítica a essa abor- 
dagem, informada pelo idioma da coprodução (Jasanof, 2004), leva-nos ao encontro da perspectiva argumentativa de Fisher e Forester (1996) quando esta ressalta que a própria formulação dos "problemas públicos" tem como base valores sociais, e que as soluções encontradas pela política são resultado tanto do conhecimento científico (de maneira mais ou menos, formalizado) como de valores. Na mesma direção, Terry Shinn e Pascal Ragouet (2008) se lançaram na controversa tarefa de demonstrar a interferência social na construção do conteúdo científico. Ao proporem uma crítica à neutralidade da ciência, argumentam que esta não só não existe como não é desejável. Essa compreensão é confirmada no universo empírico pelas ponderações dos próprios gestores ao citarem as pressões sociais e políticas, dentro e fora da máquina estatal, como condicionantes que "falam mais alto" do que os aconselhamentos de especialistas.

Identificamos, aqui, certa ambiguidade no posicionamento dos gestores que, de um lado, valorizam a ciência por sua objetividade e neutralidade - "cientificidade" - enquanto, de outro, reclamam por maior operacionalidade das pesquisas acadêmicas que deveriam comprometer-se mais com as questões públicas enfrentadas pela política. A ciência, na perspectiva dos gestores, ao "distanciar-se" dessa realidade e voltar-se mais intensamente para "suas próprias questões", perde espaço para forças políticas mais presentes - como certos movimentos sociais "com acesso privilegiado às instâncias do poder" - na orientação das políticas, como esclareceu um gestor do $\mathrm{MDA}^{7}$.

Você tem atores na sociedade, os movimentos sociais, ou pessoas que, de alguma forma, têm acesso privilegiado às instâncias de poder e que fazem uma avaliação [da política] a partir de suas próprias visões, [de modo que] as mudanças nas políticas públicas são mais orientadas pelas avaliações que chegam da sociedade civil e dos gestores públicos do que dos estudos acadêmicos.

Posição que é compartilhada por outra gestora do MMA:

O que funciona mesmo é a capacidade de organização de setores que têm interesse sobre um determinado tema; a força política, a pressão. É um outro nível de tomada de decisão... A pressão política e a questão econômica pesam mais.

A ciência aparece aqui concorrendo com outras forças sociais, mas numa posição desfavorecida. Apesar de sua força legitimadora, admite-se que ela tem poder limitado nas decisões política. Mas o que é interessante de se registrar é a visão de que o campo científico e a sociedade, ou alguns segmentos da sociedade, são vistos como entes separados (mas idealmente complementares). Chamou a
7. O MDA possui um histórico de formação e atuação em consonância com os movimentos sociais, tendo sido mais amplamente acionado este discurso neste ministério. 
8. Ficamos sabendo, através de um assessor do MDA, que o ministro, ao tomar conhecimento de nossa pesquisa, tinha sido "o único" a saber sobre o que tratava a evidencebased policy (EPB) e a reconhecer sua importância. Não por acaso, esse ministro era um profissional da área da saúde (médico), justamente onde a EBP firmou-se com seus instrumentos de atualização e aproximação dos profissionais à produção acadêmica.

9. Esse levantamento criterioso da bibliografia é um dos instrumentos que compõem a caixa de ferramentas proposta pela abordagem da PBE, visando facilitar o acesso ao conhecimento por parte dos gestores. A esse respeito ver Laurent et alii, 2009. atenção a compreensão de que não cabe a eles - gestores - produzir seu próprio entendimento sobre uma matéria a partir do conhecimento disponível, apesar de todos terem formação universitária e boa parte (pelo menos 15 entre os 37) com nível de pós-graduação. A ideia que prevalece é a de que caberia aos pesquisadores responder diretamente às questões de interesse do governo, indicando, objetivamente, soluções para determinados problemas, reforçando-se, assim, uma suposta superioridade da racionalidade científica e, ao mesmo tempo, seu caráter instrumental.

Cabe aqui um parêntese para uma reflexão crítica sobre a condução da pesquisa e os limites que ela impôs, inicialmente, à compreensão dos gestores sobre as questões acerca da relação entre ciência e política. No decorrer da pesquisa, fomos levadas a perceber que a questão por nós colocada - "Qual a contribuição do conhecimento científico na tomada de decisões" - soava como algo fora do contexto. Passamos a entender que esta questão fora formulada com base numa bibliografia e em realidades distintas daquela com a qual estávamos confrontadas. Em outras palavras, a questão orientadora da pesquisa não havia sido formulada com base no conhecimento prévio da realidade sobre a qual estaríamos investigando, mas com base na bibliografia gestada em países de língua anglo-saxã (principalmente) ou em experiência de organismos internacionais. Assim explica-se o estranhamento ${ }^{8}$ por parte dos entrevistados a respeito dos objetivos da PBE que era também o objetivo central da pesquisa, qual seja: identificar as formas como o conhecimento científico é acionado na formulação de políticas públicas e as principais lacunas de conhecimento que pudessem ser preenchidas com a produção acadêmica disponível, nos moldes da revisão sistematizada da bibliografia que seria realizada por nós ${ }^{9}$.

A proposta de aportar subsídios científicos para ampliar objetivamente as possibilidades para as tomadas de decisão não era reconhecida como algo comum ou mesmo de alguma utilidade. Nessa direção, cabe citar que os relatórios por nós produzidos apresentando o resultado das discussões com os grupos focais, e devolvidos aos gestores, não tiveram repercussão nos ministérios. Contudo, esse estranhamento por parte dos gestores públicos não significa que o conhecimento científico esteja ausente nesse processo. Verificamos que outros mecanismos e procedimentos preenchiam essa função, o que exigiu uma inflexão da pesquisa acompanhada de uma reflexão sobre nossa própria compreensão cerca do papel da ciência nas políticas públicas.

A relação dialógica com nossos entrevistados levou-nos a ampliar nossa percepção inicial sobre a relação entre ciência e política pública, de modo a questionar a compreensão de que haveria um vetor unilateral de comunicação partindo da ciência 
para a política, o que já estava problematizado pela literatura especializada que ficou conhecida como a "nova sociologia da ciência".

A aproximação da política no processo de construção do conhecimento é valorizada, no universo pesquisado, como forma de democratização desse conhecimento no sentido de gerar benefícios públicos. Nessa direção, convém citar Silvio Funtowicz e Jerry Ravetz (1997) que defendiam a construção de comunidades de pares ampliadas para equacionar essa relação. Ainda no contexto normativo, procurando a melhor maneira de facilitar a contribuição da ciência para a política, propõem a formação de fóruns ("comunidades de pares") na qual participariam não apenas pesquisadores e representantes do Estado, mas também entidades da sociedade civil, com a tarefa de auxiliar nas tomadas de decisão dentro da própria comunidade científica, tanto em termos da escolha dos objetos de pesquisa como no sentido de escolher os caminhos de pesquisa que tornariam estes conhecimentos mais úteis para o bem-estar comum ${ }^{10}$.

Ao fechar o parêntese e retornando à análise das percepções dos gestores sobre o papel da ciência, encontramos aqui um aparente paradoxo: apesar de valorizarem a objetividade e a neutralidade científica, os gestores questionam a hierarquia na qual a ciência está assentada, defendendo a necessidade de uma ciência mais próxima e atenta às necessidades da política. Em síntese: os discursos dos gestores, em geral, alinham-se ao mesmo tempo às perspectivas tecnocráticas acerca da ciência como conhecimento objetivamente formulado e às perspectivas que questionam frontalmente a hierarquia valorativa desse saber. Poderíamos inferir que esta posição aparentemente contraditória se enraíza, de um lado, na legitimidade social do conhecimento científico como parâmetro de objetividade e de verdade; e, de outro, na representação da ciência como uma "torre de marfim", distante da sociedade. Desta maneira independente do que pensem os gestores sobre a responsabilidade social da ciência ou sobre a (necessária) interferência de aspectos extraobjetivos no processo de produção científica, a reiteração da objetividade ("cientificidade") permanece operante quando esse tipo de conhecimento é mobilizado nas arenas de disputa dentro e fora do Estado. Esta problematização, promovida pela escuta das narrativas dos gestores, deságua na questão da autonomia científica. Deveria então a ciência atender às demandas das políticas públicas? Se nos limitarmos aos gestores escutados, a visão predominante é de que sim, um conhecimento construído em conjunto seria mais útil. Contudo, há os que reconhecem a necessidade de uma autonomia que daria mais força à dimensão legitimadora do conhecimento científico.

Mas, aumentar o comprometimento do conhecimento acadêmico com as questões que afetam a policy não resolveria outras "dificuldades" nessa comunicação. Essas

10. Também do lado dos pesquisadores entrevistados para essa pesquisa, encontramos uma crítica aos mecanismos de aproximação entre ciência e políticas públicas sugeridos pela abordagem da PBE, no sentido de um procedimento semelhante ao descrito acima. Um pesquisador com experiência na gestão pública aponta para a importância da constituição de fóruns que reúnam representantes da sociedade civil, incluindo as sociedades e associações científicas, e do Estado, como mais adequados para esse tipo de consulta e aconselhamento. Uma experiência citada nessa direção seriam os Conselhos Nacionais. As percepções dos cientistas ou pesquisadores sobre essa relação foram aprofundadas em outro artigo. Cf. Delatin, Carneiro \& Sandroni (2015). 
dificuldades consistem em elementos reconhecidos pelos gestores como divergências práticas que impedem a maior circulação dos enunciados e das noções (científicas) e provocam um maior afastamento em relação à ciência. No esforço dessa segmentação, os gestores argumentam que o foco dos estudos acadêmicos, dadas as próprias exigências do método científico, é normalmente muito mais específico do que o das políticas, tanto em termos dos problemas de pesquisa como em termos do universo de abrangência, o que dificultaria a operacionalização da ciência e levaria os gestores a considerarem a ciência inacessível:

É que as vezes isso [o conhecimento científico] não tem uma influência tão grande, porque a política tende a ser muito macro. Se você pegar a política de agroecologia, ela é muito genérica. Ela não tem como ser muito diferente disso. Então, questões mais concretas, pontuais, em que a pesquisa é fundamental, ela não tem, necessariamente, um peso muito grande na formulação da política. [...] Mas as coisas concretas da agroecologia, o impacto disso pro solo, pra manutenção da biodiversidade onde se trabalha com a agroecologia ou não, todas são informações importantes pra quem tiver implementando as ações que decorrem da política. Mas a política em si, ela já partiu do pressuposto, por exemplo, de que a agroecologia tem um impacto mais positivo do que uma agricultura mais baseada em químico (assessor do MMA, cursando o doutorado).

A mesma compreensão é compartilhada por outro gestor do mesmo ministério:

Eu acho que [o conhecimento científico] não ajuda tanto, não tem tantas condições de a própria pessoa se aprofundar e tal, porque a própria dinâmica do serviço público é assim, acelerada. E na academia você trabalha com um conjunto restrito de problemas, você tem um olhar para determinada coisa. Então o cientista, eu falaria um pouco pensando no Thomas Kuhn, ele trabalha com um conjunto restrito de problemas, ele consegue aprofundar. Já o gestor público, ele trabalha com um conjunto enorme de problemas, com um conjunto de informações que ele não consegue aprofundar. Então eu acho que ajuda, mas não ajuda tanto por causa das diferenças de tempo, de dinâmica, da vida do cotidiano que não é parecida. Então, eu acho que esse é um problema e é por isso que não dialoga tanto. [...] o cientista tem um conhecimento mais específico e mais aprofundado. O nosso é mais amplo e a gente não consegue aprofundar tanto (assessor com mestrado).

A falta de conhecimento dos pesquisadores sobre a máquina burocrática é outro critério apontado como limitador da geração de um conhecimento que possa ser 
mobilizado pelos gestores, o que contribui para a representação da ciência e do cientista como "teórico" ou "afastado da realidade". Entende-se que, enquanto a ciência "trabalha a partir de objetivos determinados", a política "trabalha com o possível". Nessa visão, o conhecimento científico expresso, seja em textos acadêmicos, seja por intermédio de consultorias, é considerado uma forma de saber utópica se comparado ao saber suscitado em meio às políticas públicas, posto que o primeiro lida com menos limitações, principalmente no que se refere ao tempo disponível para a elaboração do trabalho. A ciência teria todo o "tempo necessário para a ponderação de diferentes pontos de vista", movimento capaz de gerar consensos bem estabelecidos e mais aprofundados. Enquanto,

\begin{abstract}
na política, você faz o possível. Na política institucional você não pode esperar que o consenso se estabeleça para colocar no papel o que você pretende. O que você pretende tem que ser colocado no papel de acordo com aquilo que se tem. [...] Por exemplo, o protocolo de Kyoto, a convenção da biodiversidade, a convenção do combate à desertificação e a mitigação dos efeitos da seca, eles representam um estado da arte de consensos políticos e burocráticos que não são necessariamente o que eventualmente desejaríamos que fosse. Mas, por ser um acordo entre partes, nos referimos sempre a eles por uma obrigação legal já que o Brasil é parte dessas convenções. O nosso olhar ultrapassa estas convenções porque temos um olhar preexistente técnico-científico, burocrático e político-institucional. Mas, o que é convencionado não é, necessariamente, o melhor, é em regra o possível (gestor-pesquisador com doutorado, MMA).
\end{abstract}

Desta maneira entende-se que a maior contribuição da ciência seria a de oferecer "evidências" (normalmente entendidas como "dados estatísticos") para a justificativa e o convencimento sobre determinadas medidas propostas. No contexto das políticas públicas, a mobilização de indicadores, traduzidos em gráficos e tabelas dotadas de uma roupagem científica, pode ser entendida como estratégias (entre diversas outras) amplamente utilizadas no sentido de gerar um fortalecimento de uma determinada agenda, ampliando a capacidade de uma questão específica se tornar objeto de atenção social, ter uma boa "imagem política" em detrimento de outras (Fuks, 2000).

Nesse sentido, não é de se estranhar que, questionados a respeito da principal "lacuna de conhecimento" identificada, os gestores citem as informações numéricas a respeito do universo a ser compreendido pela política. "Reflexões ou análises que possam contribuir para o entendimento da dinâmica ou da ocorrência de determinados problemas não são valorizadas"; é o que aponta uma gestora do MMA 
ao discorrer sobre a formulação de novas políticas de desenvolvimento sustentável voltadas para povos e comunidades tradicionais:

[...] temos carências em vários aspectos: um deles é de mapeamento de povos e comunidades, de saber números no Brasil, que têm a ver com o IBGE, com o censo. Mas enquanto não se tem o censo, que dados a gente pode utilizar? [...] esse ano a gente está com um processo grande de reestruturação da política de povos, vamos fazer cinco encontros regionais e um nacional, para que, no final do ano, a gente apresente uma cara da política de povos e de comunidades tradicionais. E aí seria muito interessante que a gente tivesse informações como estas mais mapeadas sobre o que são os povos, onde estão, qual é o número, porque isso ajuda no convencimento de políticas para esse público (gestora com mestrado, MMA).

A valorização de dados numéricos, considerados também como "mais científicos" ou "mais objetivos", explica a preferência pelas ciências da natureza, no caso do MMA, e da economia no do MDA. As ciências sociais são muito pouco mobilizadas talvez pelo fato de serem vistas como menos "objetivas", isto é, pouco sustentadas em evidências estatísticas.

O apoio dos pesquisadores no momento da avaliação da política é fortemente demandado, principalmente pelos gestores do MDA. Ao contrário do que estabelece a abordagem da EBP - o uso da ciência no decorrer do processo de formulação da política -, a prática da tecnoburocracia dos ministérios envolvidos na pesquisa é outra. A compreensão é de que se elabore a política com os instrumentos e conhecimentos disponíveis para, então, após sua implementação, seja avaliado e verificado o alcance de seus objetivos. A avaliação de políticas públicas constitui, assim, o momento privilegiado de mobilização de especialistas e de diálogo entre um e outro modo de ordenamento.

Ao partir da perspectiva da coprodução, reconhecemos que estes paradoxos aparentes são parte desta dupla percepção sobre a relação entre ciência e política que passa, de um lado, por uma imbricação completa e, de outro, por uma necessidade de separação e de construção de clivagens. Os critérios de diferenciação entre os dois campos, tal como apontados pelos gestores, são os aspectos discursivos - materiais, segundo Foucault (2010) - através dos quais é corroborada a reificação da separação entre ciência e política. 


\section{Considerações finais}

A presente pesquisa nos levou à compreensão de que, independente da percepção sobre ciência ("abrangente"; "conhecimento alienado"; "rigor metodológico"; "conhecimento objetivo", "dados estatísticos" etc.), predomina, no universo pesquisado, a representação do conhecimento científico como campo que opera por outras lógicas, diferentes daquelas da política. Por outro lado, a ciência como geradora de dados e tecnologia é vista como fundamental na geração de subsídios e fundamentação para as disputas que ocorrem no processo de formulação de políticas. A análise das narrativas dos gestores nos fez reconhecer que a ciência não é questionada enquanto forma objetiva e positiva de construção do conhecimento. Há, assim, um jogo na visão sobre o conhecimento que é permeada pela materialidade do discurso, enquanto instrumento pelo qual se disputa politicamente, e não apenas instrumento de atuação nas disputas políticas.

A reiteração da objetividade da ciência e da separação entre os dois campos, por parte dos gestores públicos, pode ser interpretada como um dos elementos da construção do lugar da ciência como legitimadora de ações e decisões. Essa ideia de separação vai na direção do que colocamos acima como "esforço de purificação" (Law, 1994) quando os dois modos de ordenamento operam uma diferenciação entre si num processo de marcação e reforço de sua própria legitimidade. Esse jogo de imbricação e separação está sempre presente na narrativa dos gestores (como também na dos cientistas-assessores) como tentativa de distinção e de valorização de seus próprios modos de percepção e de compreensão do mundo, apesar da constante imbricação entre eles. Como mostramos acima, está largamente presente nas falas dos gestores a menção a uma série de elementos pertinentes a uma forma científica de ver o mundo, tais como a ampla utilização de termos técnicos e a expressão explícita da necessidade de uma abordagem o "mais objetiva possível", perceptível na valorização dos dados quantitativos expressos por meio de tabelas e gráficos sempre presentes.

Há uma construção social ativa destes campos como separados que é corroborada pela percepção das diferenças entre as práticas de gestores e cientistas, tais como as diferenças em termos de espaço de construção, escopo epistemológico, limites à reflexão, tempo para realização de análises, entre outros aspectos ressaltados pelos gestores, o que os leva a se colocarem numa situação de incapacidade de operarem, por si próprios, instrumentos analíticos da ciência para interpretarem as matérias em pauta, apesar do grau de formação acadêmica que possuam. A cautela reside em não naturalizar estas clivagens, e reconhecer a cada momento a maneira como estas são acessadas para corroborar determinadas posições de poder. 
Para Jasanoff (2004), as dinâmicas do poder nas sociedades contemporâneas não podem ser compreendidas de maneira apartada das formas de constituição e circulação do conhecimento científico e tecnológico. É através deste tipo de conhecimento que são moldados socialmente os discursos considerados legítimos ou ilegítimos, ou melhor mais legítimos, ou menos legítimos.

Para Foucault (2010), os enunciados, ao se produzirem, geram princípios de controle da produção de discurso. Estas formas de controle se manifestam de diversas maneiras nas mais diferentes formas de discurso, mas no caso do conhecimento científico, uma das características centrais da formulação de enunciados é a construção de princípios de coerção e de constituição de fronteiras, de delimitação muito clara entre os enunciados que podem ou não ser considerados como científicos. Em consonância com esta perspectiva, Jasanoff argumenta que a ciência e a tecnologia são agente políticos, na medida em que

o que sabemos sobre o mundo está intimamente relacionado à nossa percepção sobre o que pode ser feito, assim como à sensação de legitimidade de atores, instrumentos e cursos para a ação específicos (Jasanoff, 2004: 14, tradução das autoras).

Ao observar as imagens e experiências vivenciadas por nossos entrevistados, sobressaem os desafios colocados pelas diferenças entre os modos de fazer e os tempos da ciência e da política. Enquanto a primeira necessita cumprir um longo caminho movido por incertezas até chegar às evidências, o que exige tempo e paciência, a política necessita de urgência e de unidades discursivas bem-acabadas que podem ser facilmente utilizadas nas arenas de disputa. Além disso, contam também as dificuldades de compreensão da linguagem científica, hermética, e a distância entre as questões que interessam os cientistas e as questões que importam à política. A especificidade que orienta os estudos científicos e a generalidade que busca a política se confrontam de modo a tornar quase impossível a adaptação/tradução dos resultados das pesquisas às necessidades vivenciadas no universo da política.

Entretanto, se reconhecemos que ciência e política (politics) são coproduzidas num contexto de valorização da objetividade e da cientificidade, seria possível pensar esta relação em outros termos? O sociólogo português João Arriscado Nunes (2005), ao refletir sobre a autonomia científica, propõe ultrapassar os pressupostos da diferença entre os campos da ciência e da política na construção de teorias em diálogo com outras formas de saber. Argumenta o autor que, ao invés de se reconhecer apenas os "efeitos perniciosos" da incorporação irrefletida dos aspectos morais na construção do conhecimento, parta-se da imbricação inexorável entre as esferas 
cognitiva, estética e moral, e da não dissociabilidade entre teoria e política. A ideia é gerar um novo campo de conhecimento que agregue a pluralidade de pontos de vista em suas inúmeras sobreposições, tendo como base a noção de que qualquer teoria só adquire significação no quadro de constelações de subjetividades no qual é construída. Portanto, a geração de uma teoria crítica emancipatória depende não de sua separação em relação aos modos "irrefletidos" de conhecimento, mas sim de sua abertura para novas interseções. Neste sentido, o conhecimento científico teria uma relação explícita e direta com a política até mesmo em seu aspecto de formulação e implementação de políticas públicas.

Acrescentaríamos às elucubrações de Nunes que este movimento não pode ser feito sem que haja o cuidado de levar em consideração as hierarquias historicamente constituídas, pois há que se considerar as relações de poder estabelecidas socialmente entre os diferentes tipos de conhecimento.

\section{Science and policy on the perspective of public managers: relativizing borders}

Abstract: This article presents a reflection on the interaction between science and public policy. based on interviews with policymakers from two ministries (Agrarian Development and Environment). The aim of the study was to identify the place attributed to scientific knowledge in the policy making process. For this it was necessary to recognize the policymakers' perceptions of science. As a theoretical basis, we start from a critique of the notion of evidence-based policy, which proposes the instrumentalization of scientific knowledge by policy, in order to achieve the notion of "co-production" proposed by Jasanoff. This author argues that science, politics and culture are co-produced, being impossible to establish clear boundaries between them. We conclude that, among the interviewees, it prevails the valuation of science objectivity as a critical point to legitimate policy decisions. But, contradictorily, they also demand for greater involvement between science and government interests. It was also observed that, in spite of the difficulties noted on this interaction managers practices and discourses were permeated with references to scientific knowledge.

Keywords: evidence-based policy, co-production, policy maker, policy, science and society.

\section{Referências}

CARNEIRO, Maria José; LEITE, Sergio; BRUNI, Rejan. Conhecimento científico e políticas públicas: mobilização e apropriação do saber em medidas de conservação da Mata Atlântica. Estudos Sociedade e Agricultura (UFRRJ), v. 17, p. 254-303, 2009.

CARNEIRO, Maria José; PALM, Juliano Luis. Informando política pública: uma revisão bibliográfica sobre Pronaf e qualidade de vida (2016-2013). Raízes, v. 36, n. 1, Jan.-Jun. 2017. 
DELATIN, Daniel; CARNEIRO, Maria José; SANDRONI, Laila Thomaz. De la investigación a la política pública: producción y circulación de conocimiento científico. Nómadas, n. 42, 2015.

EZHARI, Yaron. Science and the political imagination in contemporary democracies. In: JASANOFF, S. States of konowledge: the co-production of science and social order. London: Routledge, 2004.

FISCHER, Frank; FORESTER, John (Orgs.). The argumentative turn in policy analysis and planing. London: Taylor \& Francis, 2002.

- The argumentative turn in policy analysis and planning. Durham (NC): Duke University Press Books, 1993.

FREY, Klaus. Políticas públicas: um debate conceitual e reflexões referentes à prática da análise de políticas públicas no Brasil. Planejamento e Políticas Públicas, n. 21, Jun. 2000.

FOUCAULT, Michel. A ordem do discurso. São Paulo: Loyola, 2010.

FUKS, Mario. Definição da agenda, debate público e problemas sociais: uma perspectiva argumentativa da dinâmica do conflito social. Bib, n. 49, p. 79-94, 1오. Sem. 2000.

FUNTOWICZ, Silvio; RAVETZ, Jerry. Epistemologia política: ciencia con la gente. Barcelona: Icaria Editorial, 2000.

_. Ciência pós-normal e comunidades ampliadas de pares face os desafios ambientais. História, Ciências, Saúde-Manguinhos, v. 4, n. 2, p. 219-230, Out. 1997.

GRISA, Cátia. Políticas públicas para a agricultura familiar no Brasil: produção e institucionalização das ideias. Tese (Doutorado) - Universidade Federal Rural do Rio de Janeiro, Seropédica, 2012.

JASANOFF, Sheila. States of konowledge: the co-production of science and social order. London: Routledge, 2004.

LATOUR, Bruno. Reassembling the social: an introduction to actor-network-theory. Oxford: Clarendon, 2005.

. Jamais fomos modernos - ensaio de antropologia simétrica. São Paulo: Editora 34, 1994. 
LAURENT, Catherine et alii. O debate sobre as abordagens evidence-based ou evidence-aware policy no campo da agricultura. Revista Sociedade e Agricultura, Ano 17, v. 2, 2009.

LAW, John. Organizing modernity. Oxford: Blackwell, 1994.

LEITE, Sérgio P. The role of policy makers in the formulation and implementation of public policy for brazilian agriculture. Latin American Perspectives, n. 43, p. 60-76, Mar. 2016,

NEVO, Isaac; SLONIM-NEVO, Vered. The myth of evidence-based practice: towards evidence-informed practice. British Journal of Social Work, v. 41, p. 1176-1197, 2011.

NUNES, João A. Teoria crítica, cultura e ciência: o(s) espaço(s) e o(s) conhecimento(s) da globalização. In: SANTOS, Boaventura de Sousa (Org.). A globalização e as ciências sociais. São Paulo, Cortez, 2005.

PULLIN, Andrew. S.; KNIGHT, Teri. M. Support for decision making in conservation practice: an evidence-based approach. Journal for Nature Conservation, v. 11, n. 2, p. 83-90, 2003.

PULLIN, Andrew S.; KNIGHT, Teri M.; WATKINSON, Andrew R. Linking reducionist science and holistic policy using systematic reviews: unpacking environmental policy questions to construct an evidence-based framework. Journal of Applied Ecology, v. 46, p. 970-975, 2009.

SARDO, A.; WEITKAMP, E. Exploring the ways environmental science is used and valued by policy-makers in Portugal: a case study. Journal of Science Communication, v. 11, n. 3, 2012.

SHINN, Terry; RAGOUET, Pascal. Controvérsias sobre a ciência: por uma sociologia transversalista da atividade científica. São Paulo: Associação Filosófica Scientia Studia; Editora 34, 2008.

SUREL, Yves. Approches cognitives. In: BOUSSAGUET, Laurie; JACQUOT, Sophie; RAVINET, Pauline. Dictionnaire de politiques publiques, p. 80-88. 2. ed. Paris: Presses de Sciences Po, 2006.

SUTHERLAND, William J.; PULLIN, Andrew S.; DOMAN, Paul M.; KNIGHT, Teri M. The need for evidence-based conservation. Trends in Ecology and Evolution, v. 19, n. 6, Jun. 2004. 
